\title{
RECURRING NIGHTMARE:
THE PLAGUE VISITS BEIJING Jane Brophy
}

Bird flu in the year of the rooster ... swine fever in the year of the pig. Next year is the year of the rat ... the plague is coming.

— Weibo user, November $2019^{1}$

C O WROTE ONE Weibo user in mid$\checkmark$ November after days of widespread rumours in the capital of the People's Republic of China (PRC) sparked panic. Then, the government confirmed it: the thought-to-be eradicated pneumonic plague had arrived in Beijing.

Pneumonic plague, a severe infection of the lungs, is one of three types of plague caused by the bacteria Yersinia pestis (of which there are many strains), the other two being bubonic (found in the lymph nodes and associated with the feared pustules of the 'Black Death' of fourteenth-century Europe) and septicaemic (found in the bloodstream). ${ }^{2}$ The bacteria is endemic in China and, while the bubonic form is more common, pneumonic is the most virulent. Left untreated, it can be fatal within eighteen to twentyfour hours, although if treated quickly and effectively with appropriate antibiotics, it is easily contained. The most common way of contracting the plague in China is through the bite of an infected flea or by coming into contact with (or even consuming) an infected rodent. Pneumonic plague can spread through respiratory droplets from an infected patient who sneezes or coughs, for example. In the southern, central, and western parts of China where the rodent population is high (increasing desertification and drought provide favourable living 
conditions) and rural life makes contact with disease carriers more likely, large public health campaigns since 1949 have been successful in mobilising teams of villagers to engage in pest-control work. Teams of rat catchers still trap and test rats periodically to monitor them for possible outbreaks and changes to the

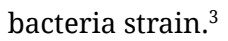

For Beijingers, however, the threat of the plague is a distant memory, as seen in a World Health Organisation (WHO) map of the global distribution of plague in 2016 (see opposite). ${ }^{4}$ Thus the news, first appearing via a quickly deleted social media post by a doctor working at central Beijing's Chaoyang Hospital in early November, revealed that two plague patients had been mysteriously 'transported' from a hospital in Inner Mongolia. ${ }^{5}$ Despite attempts by China's Centre for Disease Control and Prevention (CDC) to limit further public discussion, rumours spread rapidly as the hospital ordered medical students working there to stay at home and all the seating in the emergency waiting area was replaced. ${ }^{6}$ Government attempts to take control of the narrative and quell panic only fuelled it by providing an incomplete picture of what had actually taken place. This revived fearful memories of the mismanagement of SARS ('severe acute respiratory syndrome' or 'bird flu') at the same hospital in 2003, where a lack of public communication is believed to have resulted in the spread of the disease. ${ }^{7}$

Occasional cases of plague infection are not rare in interior parts of China and are only sometimes lethal. But the presence of two infected patients in one of Beijing's premier hospitals sent social media users into fits of panic and made international headlines. ${ }^{8}$ Locals on social media demanded to know more about the circumstances under which the patients were transferred to Beijing: Had the patients been taken by public transport? Had they been on a plane? What steps had health officials taken to prevent the potential airborne spread of the disease?

Further investigative reporting by the English-language media outlet Caixin, which obtained an internal CDC brief, suggested this recent outbreak had been contained. ${ }^{9}$ It revealed that the highly unusual step of transferring the two patients (a married couple) more than 800 kilometres to the capital - when normal protocol is to 


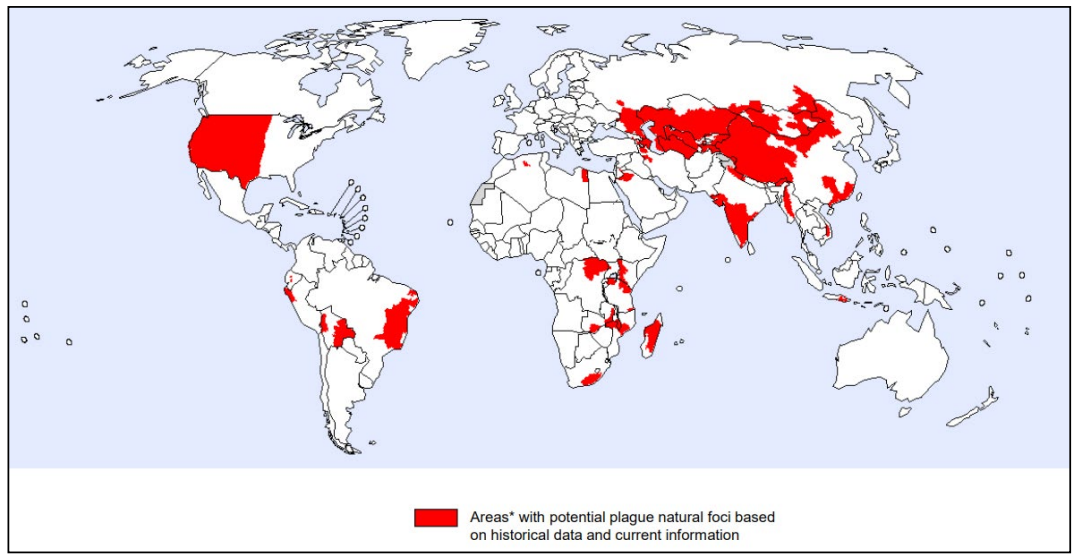

Global distribution of natural plague foci as of March 2016

Source: WHO/PED, as of 15 March 2016

isolate and treat patients as quickly and as locally as possible - was taken because of a delayed diagnosis and the need for more specialised facilities to treat the infection in its advanced stage. $^{10}$ They were, moreover, transferred by ambulance. After their short stay in the emergency department at Chaoyang Hospital, the couple was taken to the smaller Ditan Hospital, which specialises in infectious diseases. The couple's son and daughter were being monitored, and others at the Chaoyang Hospital who may have come into contact with them were being preventatively treated. While all this turned out to be something of a 'storm in a teacup', greater transparency at the outset could have prevented the panic and suspicion.

While the memory of plague might not be so vivid for today's citizens, China has a long history with the bubonic and pneumonic plagues. The third great plague in documented history began in 1855 in Yunnan. The two previous outbreaks were those suffered by the Byzantine empire in 541 and 542 and the Black Death that killed one-third of Europe's population between 1346 and 1353 . Driven by increased global trade and an influx of the ethnic majority Han people seeking to exploit the natural resources of south-western China (where many rats and fleas were carriers of plague bacteria), the 


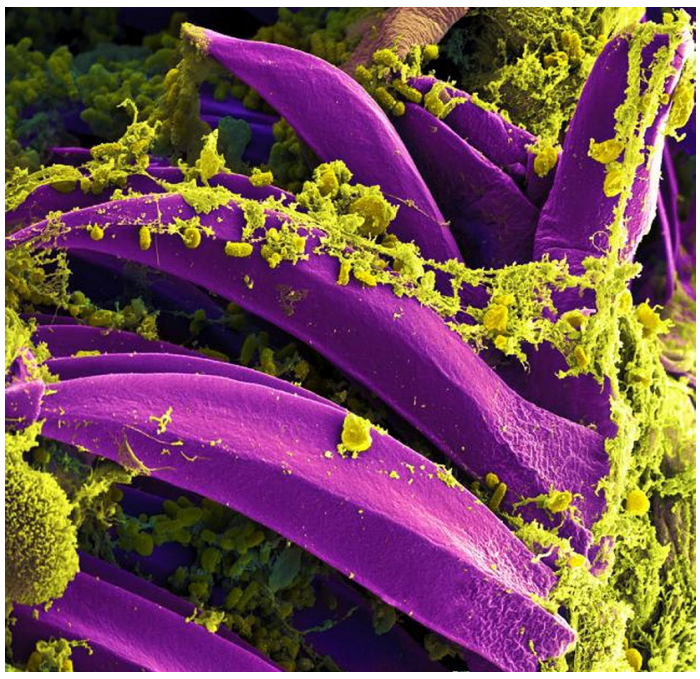

Under the lens: The bubonic plague Source: U.S. Dept. of Health \& Human Services, Flickr

nineteenth-century 'Third Plague' bloomed into a global pandemic of (primarily) the bubonic strain, which was spread by rats and fleas on trading ships. In China and India alone, twelve million people died. The threat was considered active in China until 1960 when cases reported to the WHO fell to below 200 per year. ${ }^{11}$ Despite this, or perhaps because of it, as admitted by health authorities in Inner Mongolia, public health campaigns to raise awareness of plague prevention and control have not been as visible in recent decades. Caixin spoke to residents of Inner Mongolia who were surprised to learn that the plague was an ever-present threat as they had not lived through a public education campaign. ${ }^{12}$

This 2019 case highlighted two uncomfortable truths: the persistent health divide between rural and urban areas, and the potential impact climate change is having on plague control efforts. According to the investigation by Caixin, the couple was from Sonid Left Banner, a country-level division of Xilingol League in remote central Inner Mongolia. They contracted the plague while carrying out pest-control work. In the past fifty years, China has recorded more than 1,000 cases of the plague and 183 deaths, with the hardest hit region being north-western Qinghai. ${ }^{13}$ In May 2018, the Xinhua 
News Agency reported an explosion of the rat population in Inner Mongolia, which it attributed to 'recent persistent drought' and a vague reference to 'climate change'. ${ }^{14}$ For people looking for examples of the interplay between climate change and epidemiological trends around the world, this might represent a new but ongoing challenge to plague eradication. As well as examining rising rodent numbers, a small number of scientific studies have begun to explore the relationship between climate and the plague cycle, suggesting temperature extremes play a factor in increased transmission. ${ }^{15}$
In response to the increased rodent population in 2018, the central government allocated twelve million yuan for pest control in the region, meaning more residents doing the frontline work in direct contact with rodents. The case of the couple from Inner Mongolia suggests that concurrent investment in healthcare infrastructure and resources to protect the health of those workers will be a crucial piece of managing the plague. It remains to be seen whether 2020, the year of the rat, will also be the year that the rat-borne plague returns to Beijing - and beyond. 
This text is taken from China Story Yearbook: China Dreams, edited by Jane Golley, Linda Jaivin, Ben Hillman and Sharon Strange, published 2020 by ANU Press, The Australian National University, Canberra, Australia.

doi.org/10.22459/CSY.2020.05B 